\title{
Methyldiethanolamine and Piperazine as Extractant in Emulsion Liquid Membrane for Carbon Dioxide Removal
}

\author{
Kamarudin K. S. N., Dolmat N., and Najib S. B. M.
}

\begin{abstract}
Emulsion liquid membrane was formulated using MDEA and piperazine as extractant in sodium hydroxide solution. Span-80 in the organic solution acts as surfactant to stabilize the formation emulsion. The effects of MDEA/PZ ratio on emulsion stability and $\mathrm{CO}_{2}$ absorption were investigated. $\mathrm{CO}_{2}$ absorption was carried out in rotating disc contactor (RDC) column and gas chromatography (GC) was used to determine the amount of $\mathrm{CO}_{2}$ leaving the column. This study showed that $8 \%$ v/v Span-80 has produced a stable emulsion. The emulsion was able to remove $60.3 \%$ of $\mathrm{CO}_{2}$. In the presence of methane (CH4), $54.1 \%$ of $\mathrm{CO}_{2}$ and $13.2 \%$ of $\mathrm{CH} 4$ were removed from $\mathrm{CH}_{4} / \mathrm{CO}_{2}$ mixtures. The finding demonstrates the promising technique of ELM for $\mathrm{CO}_{2}$ removal.
\end{abstract}

Index Terms - Emulsion liquid membrane, carbon dioxide, removal, stability.

\section{INTRODUCTION}

$\mathrm{CO}_{2}$ that emitted to the environment can be reduced by the separation process such as chemical and physical absorption, adsorption, cryogenic separation and membrane separation [1]-[3]. Absorption is a process in which soluble components of gas mixture are dissolved in a liquid phase. $\mathrm{CO}_{2}$ absorption by using alkanolamines has been widely used in plants such as ammonia plant [4]. Aqueous solutions of alkanolamines such as monoethanolamine (MEA), diethanolamine (DEA), di-isopropanolamine (DIPA), and N-methyldiethanolamine (MDEA) are the possible solvent that mostly used in the industry for $\mathrm{CO}_{2}$ absorption.

For several decades, MEA was exclusively used as extractant for $\mathrm{CO}_{2}$ absorption. However the used of MDEA as a solvent for $\mathrm{CO}_{2}$ absorption becomes more effective than MEA due to the low operating costs, less corrosive and high $\mathrm{CO} 2$ capacity ( $1 \mathrm{~mol} \mathrm{CO} 2 / 1 \mathrm{~mol}$ amine) [5]. The slower rate of reaction between $\mathrm{CO}_{2}$ and MDEA was overcome by the addition of activator such as piperazine (PZ) [6]. PZ is a cyclic diamine structure which each mole of $\mathrm{PZ}$ can theoretically react with two moles of $\mathrm{CO}_{2}$ [7]. It was also reported that the reaction rate of $\mathrm{PZ}$ with $\mathrm{CO}_{2}$ was higher than MEA [8].

Manuscript received October 30, 2014; revised January 1, 2015. This work was supported in part by the Ministry of Higher Education Grant 4F438. Methyldiethanolamine and piperazine as extractant in emulsion liquid membrane for carbon dioxide removal

K. S. N. Kamarudin and S. B. M. Najib are with the Faculty of Petroleum and Renewable Energy Engineering, Universiti Teknologi, Malaysia (e-mail: sozana@petroleum.utm.my, balqisnajib@gmail.com).

N. Dolmat was with Faculty of Petroleum and Renewable Energy Engineering, Universiti Teknologi Malaysia. Now, she is with the Petronas Research Sdn. Bhd, Malaysia (e-mail: nor.deela@gmail.com).
MDEA activated by $\mathrm{PZ}$ was proven as a promising solvent for $\mathrm{CO}_{2}$ absorption and has been investigated by many researchers [9]-[13]. However, the presence of acid gases $\left(\mathrm{CO}_{2}\right.$ and $\left.\mathrm{H}_{2} \mathrm{~S}\right)$ in any alkanolamine solutions during absorption process leads to the corrosion problem. Corrosion becomes one of the serious problems in $\mathrm{CO}_{2}$ absorption that always occurred in some plant locations such as regenerator, boiler and absorber [14], [15]. It was reported that stated that about 9 million of dollars are annually spent to mitigate the corrosion from the plant systems [16]. Besides, about $25 \%$ of maintenance cost was spent in the corrosion problems in the removal of acid gases plants [17]. Zhoa et al. [18] mentioned that the corrosion rate was increased with the increasing of PZ in MDEA solution. The blended of MDEA-PZ was more corrosive than AMP-PZ blended but less corrosive compare to MEA-PZ, MEA-AMP and MEA-MDEA blended [19].

Recently, liquid membrane separation becomes one of the alternative technologies for $\mathrm{CO}_{2}$ absorption. The separation occurs when the solute permeate through the liquid phase from a feed phase to receiving phase. There are three types of liquid membranes including bulk liquid membrane (BLM), supported liquid membrane (SLM) and emulsion liquid membrane (ELM). ELM separation technique was proven as a potential way to remove any pollutants such as metal from wastewater or effluents [20], [21]. However, $\mathrm{CO}_{2}$ absorption by using ELM is still a new technology and need further investigation. The application of ELM is limited because of the emulsion stability problem. Unstable emulsion leads to breakage of emulsion particle that leads to the loss of internal phase [22]. Emulsion stability was influenced by some factors including the concentration of surfactant and the condition of emulsification process.

Typically, ELM is prepared by homogenizing two immiscible liquids. The particles formed are dispersed in the continuous phase. Very large surface area to volume ratios is one of the advantage of ELM [23]. The fast separation process can be achieved by ELM due to the small thickness of the membrane (organic film) and large surface area [24]. In addition, other advantages of ELM are simple operation, high efficiency and scope for c ontinuous operation [25]. ELM provides high mass transfer area than the other two membranes because thickness of the membrane is very small while the surface area is high that resulting in very fast separations [26]. However, there are some issues regarding emulsion stability that can cause a membrane leakage that limited their commercial potential. Thin membranes tend to leak or rupture and the inner phase can swell cause a unstable membrane. Separation process by using ELM also has a low 
operating cost compare to the conventional separation method [27]. This paper presents stability of emulsion and the percentage of $\mathrm{CO}_{2}$ absorbed by the ELM method using MDEA and piperazine as extractants.

\section{EXPERIMENTAL PROCEDURE}

\section{A. Emulsion Preparation}

Emulsion liquid membrane (ELM) was formed by homogenizing the aqueous and the organic solution. Aqueous solution consists of monodiethanolamine (MDEA), piperazine (PZ) and sodium hydroxide $(\mathrm{NaOH})$ solution while organic phase consists of Span-80 as surfactant and kerosene. $100 \mathrm{~mL}$ of aqueous phase was prepared by mixing MDEA and PZ into $0.1 \mathrm{M} \mathrm{NaOH}$ solution. The solution was stirred for 15 minute. For organic solution, $100 \mathrm{~mL}$ of organic phase was prepared by adding Span- 80 into the kerosene oil and stirred for 15 minute. The stirring speed and temperature of the heating plate for aqueous and organic phase solution were fixed at $700 \mathrm{rpm}$ and $27^{\circ} \mathrm{C}$ respectively. For the preparation of emulsion, the high performance disperser Ultra Turrax ${ }^{\circledR}$ T25 with $18 \mathrm{G}$ mixing shaft was used. $100 \mathrm{~mL}$ organic phase mixture was placed in the beaker and the aqueous phase mixture was poured drop wise in the beaker containing the organic phase and homogenized to produce water-in-oil emulsion.

\section{B. Stability of Emulsion}

The stability of emulsion was measured based on sedimentation of particles. Sedimentation is an early process that leads to the emulsion breakdown after a certain time [28]. The emulsion becomes less homogenous as it starts to settle. Stability test of the emulsion was conducted before $\mathrm{CO}_{2}$ absorption process for different concentration of Span-80 and different MDEA/PZ concentration. The stability of emulsion was also measured after $\mathrm{CO}_{2}$ absorption. To do the measurement, the emulsion was filled in the graduated test tubes and left in the room for 24 hours. The sedimentation process was demonstrated by the presence of another layer on the top of emulsion while emulsion breakdown was indicated by the presence of layers on the top and bottom of the emulsion [29]. The determination of emulsion stability was based on the percentage of emulsion sedimentation where the volume of top layer was measured.

$$
\% \text { stability }=\frac{V_{T}-V_{S}}{V_{T}} \times 100 \%
$$

where

$$
\begin{gathered}
V_{T}=\text { Total volume }(\mathrm{ml}) \\
V_{S}=\text { Top layer volume }(\mathrm{ml})
\end{gathered}
$$

In addition, the viscosity of the organic phases and aqueous phases were measured using Programmable Rheometer Brookfield Model DV-III at room temperature. The viscosity of the organic phases was measured to estimate the diffusivities of the emulsion. A spindle type 00 was used to test the viscosity and motor speed at $60 \mathrm{rpm}$.

\section{Carbon Dioxide Removal}

Rotating disc contactor (RDC) column (Fig. 1) that connected to the gas chromatography (GC) was used for $\mathrm{CO}_{2}$ absorption study. The column was filled with $200 \mathrm{~mL}$ of the prepared emulsion. The flow rate of carbon dioxide to the column was fixed at 20 LPM (Liter per minute). The speed of the rotating disc was in a range of 450-500 rpm. The pressure of the RDC was also recorded. Gas chromatography (GC) was used to determine the amount of $\mathrm{CO}_{2}$ in the inlet and out streams of the RDC.

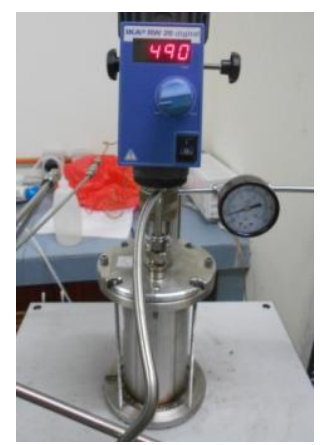

Fig. 1. Rotating disc contactor (RDC) system for $\mathrm{CO}_{2}$ adsorption study.

\section{RESUlTS AND DISCUSSION}

Fig. 2 shows stability of emulsion and the percentage of $\mathrm{CO}_{2}$ absorption at different concentration of Span-80. Emulsion containing $8 \%$ v/v of Span-80 shows the highest percentage of $\mathrm{CO}_{2}$ absorption (54.8\%) followed by $10 \% \mathrm{v} / \mathrm{v}$ Span-80 (42\%), 6\% v/v Span-80 (37.8\%), 12\% v/v Span-80 (35.4\%). The emulsion contained $0.5 \%$ v/v Span-80 and $1 \%$ v/v Span-80 were not tested for $\mathrm{CO}_{2}$ absorption since it formed 3 layers immediately after emulsification. This phenomenon indicates the occurrence of emulsion breakage. For $2-12 \%$ v/v Span-80, the emulsions formed 2 layers due to sedimentation. Sedimentation occurs as the emulsion droplets collides and merges to form the larger droplets and started to settle at the bottom of graduated test tube. Size of emulsion droplets is directly proportional to the velocity of sedimentation process [30], [31].

Further addition of Span-80 from $8 \%$ v/v to $12 \% \mathrm{v} / \mathrm{v}$ decrease the percentage of $\mathrm{CO}_{2}$ absorption from $54.8 \%$ to $35.4 \%$. This is probably due to the high viscosity of the emulsion. Several investigations also have demonstrated that by increasing the surfactant concentration, the viscosity of emulsion increased. High emulsion viscosity would decrease the diffusion and mass transfer coefficient [32]-[34].

Gas diffusion coefficient in liquid media was estimated the Based on Wilke - Chang correlation [35]. As shown in Eq. (1), the diffusion coefficien decrease when the viscosity increases.

$$
D=\left[7.48 \times 10^{-8}\right] \frac{T \sqrt{\alpha M_{2}}}{\mu_{2} \overline{\mathrm{V}}_{1}^{0.6}}
$$

where

$$
\begin{aligned}
& \alpha \text { - association constant } \\
& V_{1} \text { - molar volume of gas solute }\left(\mathrm{cm}^{3} / \mathrm{mol}\right) \\
& \mu \text { - viscosity }(m \mathrm{~Pa} / \mathrm{s}) \\
& T \text { - temperature }(K) \\
& M \text { - molecular weight of the solvent }(\mathrm{g} / \mathrm{mol}) \text {. }
\end{aligned}
$$

The viscosity and diffusion coefficient are shown in Table I. As the viscosity of the organic phase increase, the diffusion 
coefficient decreases. The decrease explains the reduction of $\mathrm{CO}_{2}$ absorption.

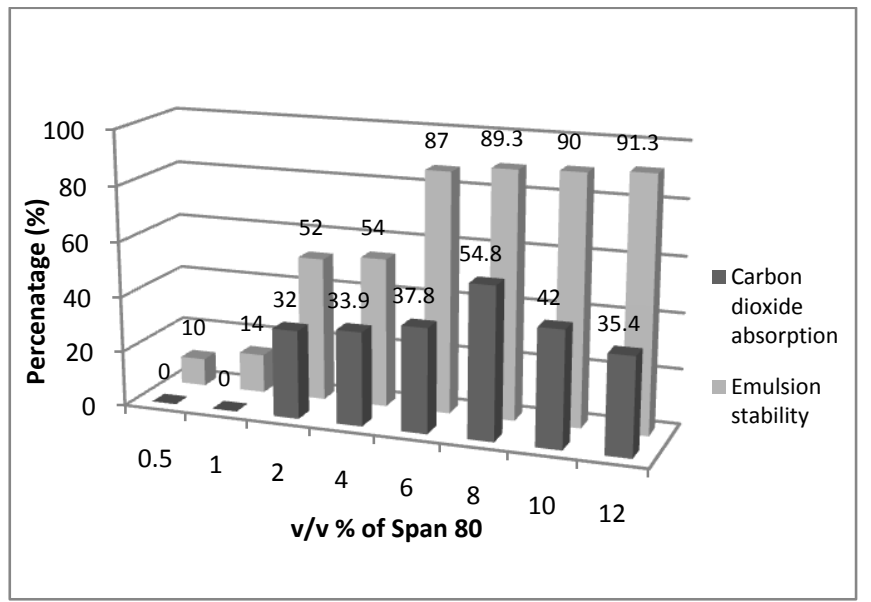

Fig. 2. Percentage of $\mathrm{CO}_{2}$ absorption and stability of emulsion at different amount of Span-80.

TABLE I: VISCOSITY AND DIFFUSION COEFFCIENT AT DIFFERENT AMOUNT OF SPAN-80.

\begin{tabular}{ccc}
\hline Span-80],$\% \mathrm{v} / \mathrm{v}$ & Viscosity, $c P$ & $\begin{array}{c}\text { Diffusion Coefficient, } \\
D\left(x 10^{3}\right)\end{array}$ \\
\hline 0.5 & 0.90 & 4.79 \\
1 & 1.12 & 3.85 \\
2 & 1.16 & 3.72 \\
4 & 1.20 & 3.60 \\
6 & 1.29 & 3.34 \\
8 & 1.36 & 3.17 \\
10 & 1.44 & 3.00 \\
12 & 1.66 & 2.60 \\
\hline
\end{tabular}

The effect of MDEA/PZ on emulsion stability and $\mathrm{CO}_{2}$ absorption was illustrated in Fig. 3. The addition PZ to MDEA in the aqueous solution increased the percentage of $\mathrm{CO}_{2}$ absorption as compared to use MDEA only. The percentage of $\mathrm{CO}_{2}$ absorption increased as the concentration of PZ increased in 8\% MDEA solution. 8\% v/v MDEA with $6 \%$ $v / v$ PZ showed the highest $\mathrm{CO}_{2}$ absorption (54.8\%). According to Mandal et al. (2001), MDEA has equilibrium loading of $1.0 \mathrm{~mol}$ of $\mathrm{CO}_{2}$ per mole of amine. However, the reaction rate of MDEA is low [36]. The reaction between $\mathrm{CO}_{2}$ and tertiary amines such as MDEA is slower than reaction between $\mathrm{CO} 2$ and primary or secondary amines [37]. Therefore, to improve the $\mathrm{CO} 2$ absorption, $\mathrm{PZ}$ was added that acts as an activator in the MDEA solution due to its ability to react faster than MDEA.

This approach is in agreement with Bishnoi et al., [38], Dang and Rochelle [39], Cullinane et al., [40] and Khalili et al., [41] that also proposed the used of piperazine as an activator to other slower alkanolamines such as MDEA. It was also reported that piperazine has a rapid reaction rate with $\mathrm{CO}_{2}$ than MEA [42], [43]. By increasing the quantity of PZ (additional of $1 \% \mathrm{v} / \mathrm{v}$ for each sample) the emulsion stability remains high.

It is expected that by increasing the quantity of MDEA and $\mathrm{PZ}$ in the emulsion formulation, $\mathrm{CO}_{2}$ absorption would increase since more MDEA and $\mathrm{PZ}$ are available to react with $\mathrm{CO}_{2}$. However, Fig. 4 shows that emulsion stability and $\mathrm{CO}_{2}$ absorption decreased as the concentration of MDEA and PZ increased. This is possibly due to the presence of MDEA and PZ that increased the viscosity of aqueous solution. Highly viscous solution requires more energy to disperse the particles in a continuous phase (organic phase). The size of particles formed would be larger for highly viscous solution. It also reduced the mass transfer of the solute in ELM system.

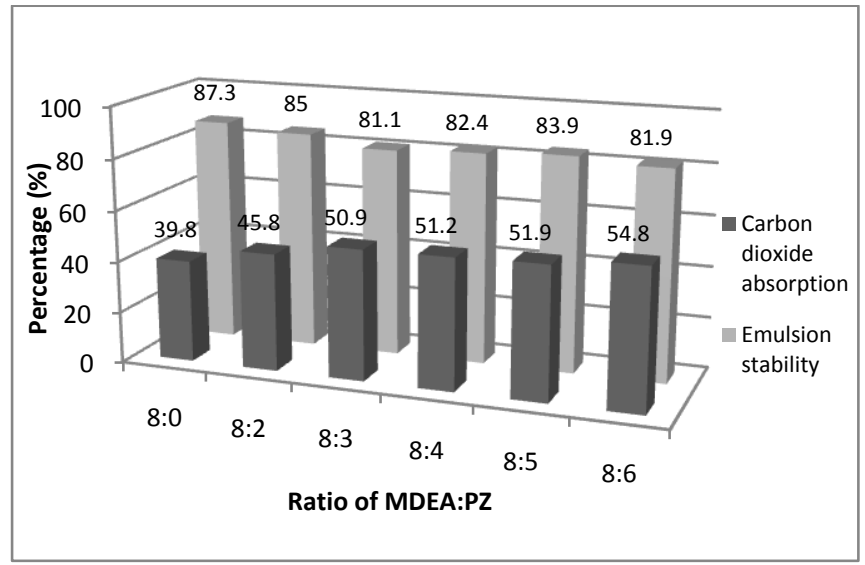

Fig. 3. Percentage of $\mathrm{CO}_{2}$ absorption and stability of emulsion at different ratio of MDEA and PZ.

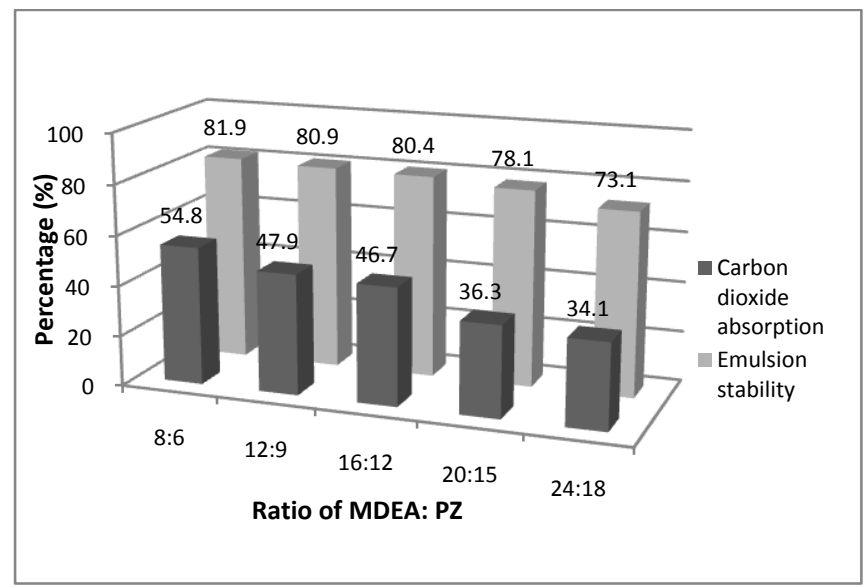

Fig. 4. The percentage of $\mathrm{CO}_{2}$ absorption and stability of emulsion at different concentration of MDEA and PZ based on ratio of $4: 3$

TABLE II: VISCOSITY OF THE EMULSION AT DIFFERENT FORMULATION

\begin{tabular}{ccc}
\hline MDEA], $\% v / v$ & {$[\mathrm{PZ}], \% v / v$} & Viscosity, $c P$ \\
\hline 8 & 6 & 1.07 \\
12 & 9 & 1.12 \\
16 & 12 & 1.45 \\
20 & 15 & 1.66 \\
24 & 18 & 2.14 \\
\hline
\end{tabular}

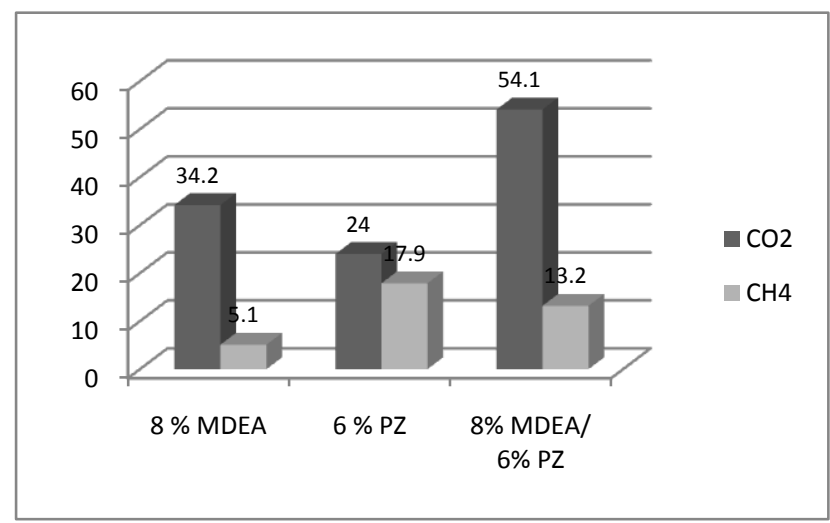

Fig. 5. $\mathrm{CO}_{2}$ removal from $\mathrm{CO}_{2} / \mathrm{CH}_{4}$ mixtures using different extractants.

The emulsion containing only $8 \% v / v$ MDEA, $6 \% v / v$ PZ and a combination of both extractants were prepared to investigate the effect of MDEA and $\mathrm{PZ}$ to the $\mathrm{CH}_{4}$ absorption 
from $\mathrm{CH}_{4} / \mathrm{CO}_{2}$ mixture. Fig. 5 shows the percentage of $\mathrm{CO}_{2}$ and $\mathrm{CH}_{4}$ for $8 \% \mathrm{v} / \mathrm{v}$ MDEA and $6 \% \mathrm{v} / \mathrm{v} \mathrm{PZ}$. The $8 \% \mathrm{v} / \mathrm{v}$ MDEA had removed about $34.2 \%$ of $\mathrm{CO}_{2}$ and only $5.1 \%$ of $\mathrm{CH}_{4}$ while $6 \% v / v$ PZ had absorbed $24 \%$ of $\mathrm{CO}_{2}$ and $17.9 \%$ of $\mathrm{CH}_{4}$.

\section{CONCLUSION}

This study has successfully investigated the favorable composition of ELM for $\mathrm{CO}_{2}$ absorption. The stability of the selected ELM remains high even after the absorption of $\mathrm{CO}_{2}$. At $8 \mathrm{v} / \mathrm{v} \%$ Span 80 , emulsion break up is negligible and only sedimentation occurred. With the ELM composition of $8 \%$ v/v Span $80,8 \%$ v/v MDEA and $6 \%$ v/v PZ, $54.1 \%$ of $\mathrm{CO}_{2}$ has been removed from $\mathrm{CO}_{2} / \mathrm{CH}_{4}$ mixture. A small amount of $\mathrm{CH}_{4}$ was also absorbed by the ELM.

\section{ACKNOWLEDGMENT}

The authors are grateful to the Ministry of Education (MOE), Malaysia and Universiti Teknologi Malaysia for the financial support on this research project.

\section{REFERENCES}

[1] B. P. Mandal and S. S Bandyopadhyay, "Absorption of carbon dioxide into aqueous blends of 2-amino-2-methyl-1-propanol and monoethanolamine," Chemical Engineering Science, vol. 61, pp. 54405447, 2006.

[2] S. H. Moon and J. W. Shim, "A novel process for $\mathrm{CO}_{2} / \mathrm{CH}_{4}$ gas separation on activated carbon fibers-electric swing adsorption," Journal of Colloid And Interface Science, vol. 298, pp. 523-528, 2006.

[3] A. Corti, D. Fiaschi, and L. Lombardi, "Carbon dioxide removal in power generation using membrane technology," Energy, vol. 29, pp. 2025-2043, 2004.

[4] R. S. Alvis, N. A. Hatcher, and R. H. Weiland, " $\mathrm{CO}_{2}$ removal from syngas using piperazine-activated MDEA and potassium dimethyl glycinate," Nitrogen Syngas, February, Athens, Greece, 2012, pp. 20-23.

[5] P. W. J. Derks, "Carbon dioxide absorption in piperazine activated N-methyldiethanolamine," $\mathrm{PhD}$ Thesis. University of Twente, Netherlands, 2006.

[6] A. L. Kohl and R. B. Nielsen, Gas Purification, 5th ed. Houston, Texas: Gulf Publishing, 1997.

[7] J. T. Cullinane and G. T. Rochelle, "Carbon dioxide absorption with aqueous potassium carbonate promoted by piperazine," Chemical Engineering Science, vol. 59, pp. 3619-3630, 2004.

[8] S. Bishnoi and G. T. Rochelle, "Absorption of carbon dioxide into aqueous piperazine: reaction kinetics, mass transfer and solubility," Chemical. Engineering Science, pp. 5531-5543, 2000.

[9] G. W. Xu, C. F. Zhang, S. J. Qin, W. H. Gao, and H. B. Liu, "Gas-liquid equilibrium in $\mathrm{CO}_{2}-\mathrm{MDEA}-\mathrm{H}_{2} \mathrm{O}$ system and the effect of piperazine on it," Industrial Engineering Chemistry Research, vol. 37, pp. 1473-1477, 1998.

[10] H. B. Liu, C. F. Zhang, and G. W. Xu, "A study on equilibrium solubility for carbon dioxide in methyldiethanolamine - piperazine water solution," Industrial and Engineering Chemistry Research, vol. 38, pp. 4032-4036, 1999.

[11] X. Zhang, C. F. Zhang, and G. W. Xu, "An experimental apparatus to mimic $\mathrm{CO}_{2}$ removal and optimum concentration of MDEA aqueous solution," Industrial Engineering Chemistry Research, vol. 40, pp 898-901, 2001.

[12] A. Samanta, S. Roy, and S. S. Bandyopadhyay, "Physical solubility and diffusivity of $\mathrm{N}_{2} \mathrm{O}$ and $\mathrm{CO}_{2}$ in aqueous solutions of piperazine and (N-methyldiethanolamine piperazine," Journal of Chemical Engineering Data, vol. 52, pp. 1381-1385, 2007.

[13] D. Speyer, V. Ermatchkov, and G. Maurer, "Solubility of carbon dioxide in aqueous solutions of N-methyldiethanolamine and piperazine in the low gas loading region," Journal of Chemical Engineering Data, vol. 55, pp. 283-290, 2010.

[14] M. J. Litschewski, "More experiences with corrosion and fouling in a refinery amine system," in Proc. of Corrosion 96, Denver, CO., National Association of Corrosion Engineers, Houston, 1996, pp. 391.
[15] M. S. D. Part, T. R. Bacon, and D. J. Edwards, "Part 2- understanding corrosion in alkanolamine gas treating plants," Hydrocarbon Processing, pp. 89-94, 1993.

[16] B. R. D. Gerus, "Detection and mitigation of weight loss corrosion in sour gas gathering systems, in $\mathrm{H}_{2} \mathrm{~S}$ Corrosion in Oil \& Gas Productions," A Compilation of Classic Papers, National Association of Corrosion Engineers, Houston, 1981, pp. 888-903.

[17] R. Tems and A. A. Zahrani, "Cost of corrosion in gas sweetening and fractionation plants," Corrosion, NACE International Paper No. 06444, 2006.

[18] B. Zhao, Y. Sun, Y. Yuan, J. Gao, S. Wang, Y. Zhuo, and C. Chen, "Study on corrosion in $\mathrm{CO}_{2}$ chemical absorption process using amine solution," Energy Procedia, vol. 4, pp. 93-100, 2011.

[19] P. Gunasekaran, A. Veawab, and A. Aroonwilas, "Corrosivity of single and blended amines in $\mathrm{CO}_{2}$ capture process," Energy Procedia, pp. 2094-2099, 2013.

[20] J. M. Barad, M. Chakraborty, and H. Bart, "Stability and performance study of water-in-oil-in-water emulsion: Extraction of aromatic amines," Industrial and Engineering Chemistry Research, vol. 49, pp 5808-5815, 2010.

[21] S. Saravanan, K. M. M. S. Begum, and N. Anantharaman, "Removal of hexavalent chromium by emulsion liquid membrane technique," Journal of The University of Chemical Technology and Metallurgy, vol. 41, no.3, pp. 333-342, 2006.

[22] M. Djenouhat, O. Hamdaoui, M. Chiha, and M. H. Samar, "Ultrasonication-assisted preparation of water-in-oil emulsions and application to the removal of cationic dyes from water by emulsion liquid membrane. Part 1: Membrane Stability," Separation and Purification Technology, vol. 62, pp. 636-641, 2008.

[23] S. E. Kentish and G. W. Stevens, "Innovations in separations technology for the recycling and re-use of liquid waste streams," Chemical Engineering Journal, vol. 84, pp. 149-159, 2001.

[24] A. Pabby and S. A. Rizhi, Handbook of Membrane Separations. Chemical, Pharmaceutical, Food and Biotechnological Applications New York: CRC Press, 2009

[25] M. Chakraborty, C. Bhattacharya, and S. Datta, "Studies on the applicability of Artificial Neural Network (ANN) in emulsion liquid membranes," Journal of Membrane Science, vol. 220, no. 1-2, pp. 155-164, 2003

[26] M. F. S. Roman, E. Bringas, I. Ibanez, and I. Ortiz, "Liquid membrane technology: Fundamentals and review of its applications," Journal of Chemical Technology and Biotechnology, vol. 85, pp. 2-10, 2010.

[27] H. C. Hayworth, W. S. Ho, J. W. A. Burns, and N. N. Li, "Extraction of uranium from wet process phosphoric acid by liquid membranes," Separation and Science Tecnhnology, vol. 18, no. 6, pp. 493-521, 1983.

[28] M. Sarbar and K. M. Al-Jaziri, "Laboratory investigation of factors affecting the formation and stability of tight oil-in-water emulsions in produced fluids," OAPEC Conference on New Technology 1, pp. 261-268, 1995

[29] C. J. Morales, U. Riebel, N. M. Guzmán, and M. Guerra, "Formulation of water in paraffin emulsions," Latin American Applied Research, vol. 41, pp. 105-112, 2011.

[30] C. Ansel, L. V. Allen, and N. G. Popovich, Disperse Systems -Pharmaceutical Dosage Forms \& Drug Delivery Systems, 8th ed., Lippincott Williams and Wilkins, Philadelphia, 2005, pp. 387-389.

[31] K. J. Lissant, "Demulsification: Industrial application," Surfactant Science Series, vol. 13, no. 1, pp. 1-38, 1983.

[32] A. Kargari, T. Kaghazchi, and M. Soleimani, "Role of emulsifier in the extraction of gold (III) ions from aqueous solutions using the emulsion liquid membrane technique," Desalination, vol. 162, pp. 237-247, 2004.

[33] R. A. Kumbasar, "Separation and concentration of cobalt from aqueous thiocyanate solutions containing cobalt-nickel by emulsion liquid membranes using TBP as extractant," Journal of Membrane Science, vol. 338, pp. 182-188, 2009.

[34] A. K. Chakravarti, S. B. Chowdhury, and D. C. Mukherjee, "Liquid membrane multiple emulsion process of separation of copper (II) from waste waters," Colloids and Surfaces A, vol.166, pp. 7-25, 2000.

[35] Q. Gan, Y. Zou, D. Rooney, P. Nancarrow, J. Thompson, L. Liang, and M. Lewis, "Theoretical and experimental correlations af gas dissolution, diffusion, and thermodynamic properties in determination of gas permeability and selectivity in supported ionic liquid membranes," Advances in Colloid and Interface Science, vol. 164, pp. $45-55,2011$

[36] X. Zhang, C. Zhang, and Y. Liu, "Kinetics of absorption of $\mathrm{CO}_{2}$ into aqueous solution of MDEA blended with DEA," Industrial Engineering Chemistry Research, vol. 41, pp. 1135-1141, 2002.

[37] G. F. Versteeg, L. A. J. Van Dijck, and W. P. M. V. Swaaij, "On the kinetics between $\mathrm{CO}_{2}$ and alkanolamines both in aqueous and 
non-aqueous solutions: An overview," Chemical Engineering Communications, vol. 144, pp. 113-158, 1996.

[38] S. Bishnoi and G. Rochelle, "Absorption of carbon dioxide in aqueous piperazine/methyldiethanolamine," American Institute Chemical Engineers Journal, vol. 48, pp. 2788-2799, 2002.

[39] H. Dang and G. T. Rochelle, " $\mathrm{CO}_{2}$ absorption rate and solubility in monoethanolamine/piperazine/water," in Proc. the First National Conference on Carbon Sequestration, May 14-17, Washington DC, 2001.

[40] J. T. Cullinane and G. T. Rochelle, "Carbon dioxide absorption with aqueous potassium carbonate promoted by piperazine," Chemical Engineering Science, vol. 59, pp. 3619-3630, 2004.

[41] F. Khalili, A. Henni, and A. L. L. East, "pKa values of some piperazines at $(298,303,313,323) \mathrm{K}$," Journal of Chemical Engineering Data, vol. 54, pp. 2914-2917, 2009.

[42] R. Dugas and G. Rochelle, "Absorption and desorption rates of carbon dioxide with monoethanolamine and piperazine," Energy Procedia, vol. 1 , no. 1 , pp. 1163-1169, 2009.
[43] S. Kadiwala, A. V. Rayer, and A. Henni, "High pressure solubility of carbon dioxide $\left(\mathrm{CO}_{2}\right)$ in aqueous piperazine solutions," Fluid Phase Equilibria, vol. 292, pp. 20-28, 2010.

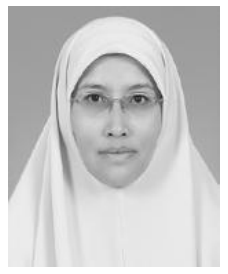

Khairul Sozana Nor Kamarudin is an associate professor in the Faculty of Petroleum and Renewable Energy Engineering at Universiti Teknologi Malaysia where she has been a faculty member since 1991. Khairul Sozana completed her Ph.D. at Universiti Teknologi Malaysia and her undergraduate studies at University of New South Wales, Australia. Her research interests lie in the area of gas separation, ranging from theory to design to implementation, with a focus on $\mathrm{CO}_{2}$ separation study. She is an associate member of Institute of Hydrogen Economy. Khairul Sozana has taught popular transport processes and separation processes courses for undergraduate program. 